\title{
Environmental impact of Huayuankou dike breach in 1938
}

\author{
Hucheng $\mathrm{LI}^{1 \mathrm{a}}$,Bingbing WANG ${ }^{2 \mathrm{~b}}$, Jun $\mathrm{YAN}^{2}$, Baorui QIU ${ }^{2}$, Fei ZHUO ${ }^{2}$ \\ ${ }^{1}$ GuangDong Research Institute of Water Resources and Hydropower, Guangzhou, 510635 \\ ${ }^{2}$ North China University of Water Resources and Electric Power, Zhengzhou, 450011 \\ a77045159@qq.com, bsy2009wangbing@163.com
}

Key words: Huayuankou dike breach; the Yellow River; flooding area; flood disaster; the ecological environment

\begin{abstract}
In 1938, the Huayuankou Dike Breach played a certain role in blocking the Japanese army westward, but the huge flooding area of the Yellow River was formed and the ecological environment extremely worsened, especially the sand and salt deposited and many other disasters occurred frequently, which not only made people in this region suffered a lot, but also left serious hazard. In recent years, people in the flooded area constructed the farmland shelter belt and farmland water conservancy facilities, decreased the salinity, silted sand and increased the soil fertility. Finally, the environment of the Yellow River Flooding Area is improved.
\end{abstract}

\section{Introduction}

Huayuankou locates in northern suburb of Zhengzhou, Henan, about 30 kilometers off the Yellow River. In Song Dynasty, the ancients built flood gates to control flood and built the village, named Guijiazhuang. In the Ming Dynasty, there was an official department minister named XU Zan built a large garden with exotic beautiful flowers and rare herbs, covering an area of 540 acres, whose south was next to the He River and north to the Yellow River. After the river was changed southward, the village and garden were engulfed by the surging Yellow River, forming the Yellow River ferry ${ }^{[1]}$. From then on, the name of Huayuankou remains.

The use of water as a soldier existed at all times and in all countries. From the records of the first burst of the Yellow River flooding in 602 BC to 1949, nearly 2000 years, there were up to 1500 times larger dike breaching, 26 times flood diversions, in which water was used as a soldier for 20 times, mostly happening in the territory of Henan, especially in the Zhengbian Area ${ }^{[2]}$.Therefore, the natural landscape of the Yellow River delta is changed, and the social and economic life in the lower reaches of the Yellow River is influenced, and the ecological environment of the Yellow River delta is greatly affected. In 1938 the Kuomintang in Huayuankou, Zhengzhou blow up the south bank of the Yellow River levee, resulted in the most serious and the longest (9 years) flood disaster in the Yellow River in resent 300 years. It spread from the northwest to the southeast about $400 \mathrm{~km}$ long, 30-80km wide and caused huge losses to the people along the river.

In June 1938, in order to prevent the Japanese invaders westward along the Longhai line and attack Wuhan along Pinghan line ${ }^{[3]}$, Chinese troops in Zhaokou, and Zhengzhou port dug the Yellow River levee, with surging Yellow River flowing down vigorously, which flowed through more than 60 counties in Henan, Anhui and Jiangsu provinces, and arrived into the sea from the Huai River, forming a huge flood area. This event forced the Japanese to mass in the east of the Yellow River flooding area and stopped the pace to offend westward Longhai line, thus Zhengzhou danger eased. Meanwhile, it made the Japanese army change the plan of Wuhan battle, and the attack of main force along the Huai River upstream change to go along the Yangtze River. In 
addition, due to the Yellow River breach, flood also appeared in Huai River. Bengbu Bridge of the Jinpu railway was destroyed and roads were flooded, which increased troop obstacles ${ }^{[4]}$. In addition, this dike breaching in the Yellow River also lagged the economy in the region occupied by Japanese and destroyed the Japanese colonial policy. Flood in the Yellow River likes a natural barrier in the northwest region, so that Luoyang, Zhengzhou and other places could isolate from the war zone, to lay a solid foundation for the construction of a long war in the northwest.

\section{The impact of environmental deterioration of Huayuankou}

The statistical results of destroyed houses in some counties in the Yellow River flooding area in Fig. 1 shows such a great number of affected regions and victims due to the breaching dike of the Yellow River. After the dike breach, the Yellow River surged and flowed down vigorously, which flowed through more than 60 counties in Henan, Anhui and Jiangsu provinces, and arrived into the sea from the Huai River, forming a huge flooding area. During this period, the original Yellow River course vanished and all of the water began from Huayuankou, flowed southward through Jialu River, Ying River, Go River and Huai River, into the Hongze Lake, Gaoyou Lake, through the JingHang Canal into the Yangtze River, and finally arrived into East China Sea. It caused a series of problems, such as environmental deterioration, the agricultural depression, economic recession and refugees in exile.

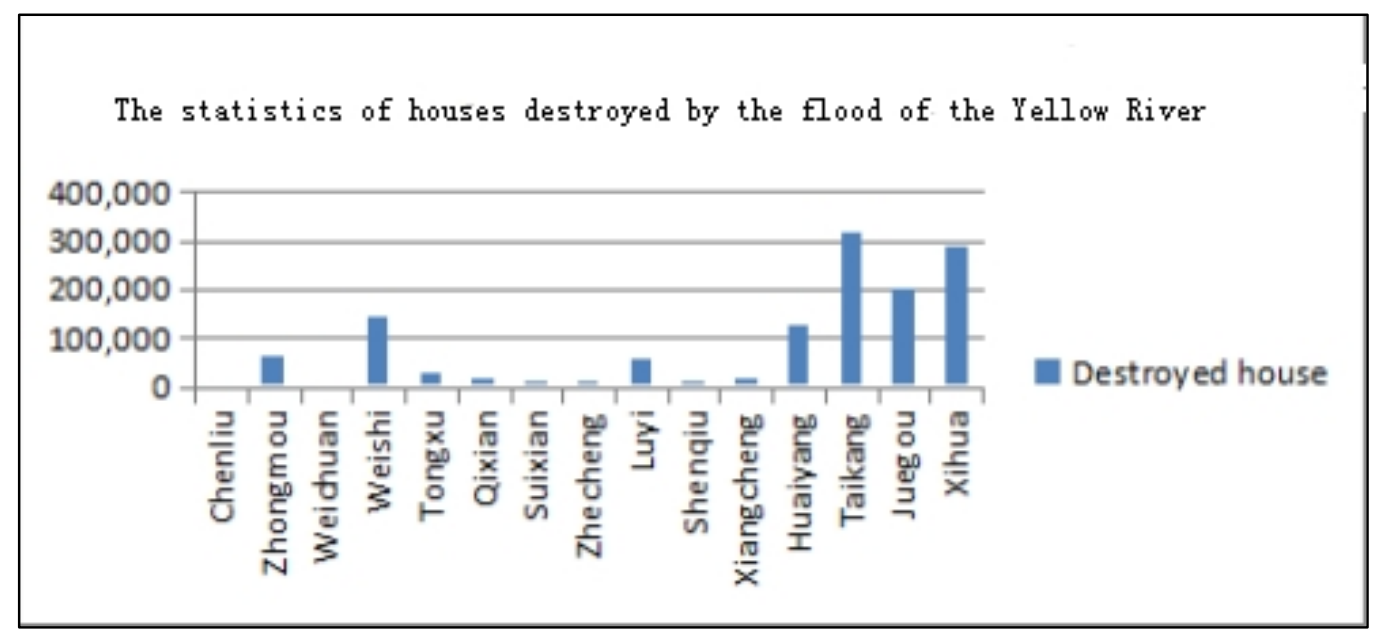

Fig. 1 The statistics of houses destroyed by the flood of the Yellow River

The worst effect of the dike breach in the Yellow River is causing environmental deterioration. A large number of sand deposition resulted in water system disorder of Huai River, heavenly stems, branches congestion, and flow impeded, triggering new flooding. In tributaries downstream, due to blockage of the mast expansion, a big belly river or a long lake occurred. In addition, due to the Yellow River tributary, the clear water can not fall, water runs backward, sediments deposit in the branch river, and the tributary is silted up. Previously, there were some high places became the lower area for the erosion. While some of the previous lower places turned into high land because of deposition. Therefore, the high places turned higher, the low places become lower. In the flooding area of Central Plains, several main rivers, such as the Ying River, Jialu River, Sha River, Hong River, had silted up. During period of the rainy season, floods often occur because of the terrain to the level of disparity, and the rivers and ditches blockage. But after the rainy season, because of a serious lack of water, a vast barren zone is formed in East Henan. More ever, because of the blockage of the Yellow River and covering the wells by soil, the problem of drinking water for the victims became severe. 
The Yellow River put 100 tons of sediments into the Huai River Basin, the average deposition thickness in 3-5M, at least $1-2 \mathrm{~m}$, thicker $7-8 \mathrm{~m}$, and even more than 10 meters, changed the underlying surface ${ }^{[1]}$. Most of the original alluvial soil is buried in deep underground, so that the original soil type and fertility in East Henan have changed. A large area of sand land, especially large sand erosion, through the windy winter and spring drought in the East Henan cause serious soil desertification.

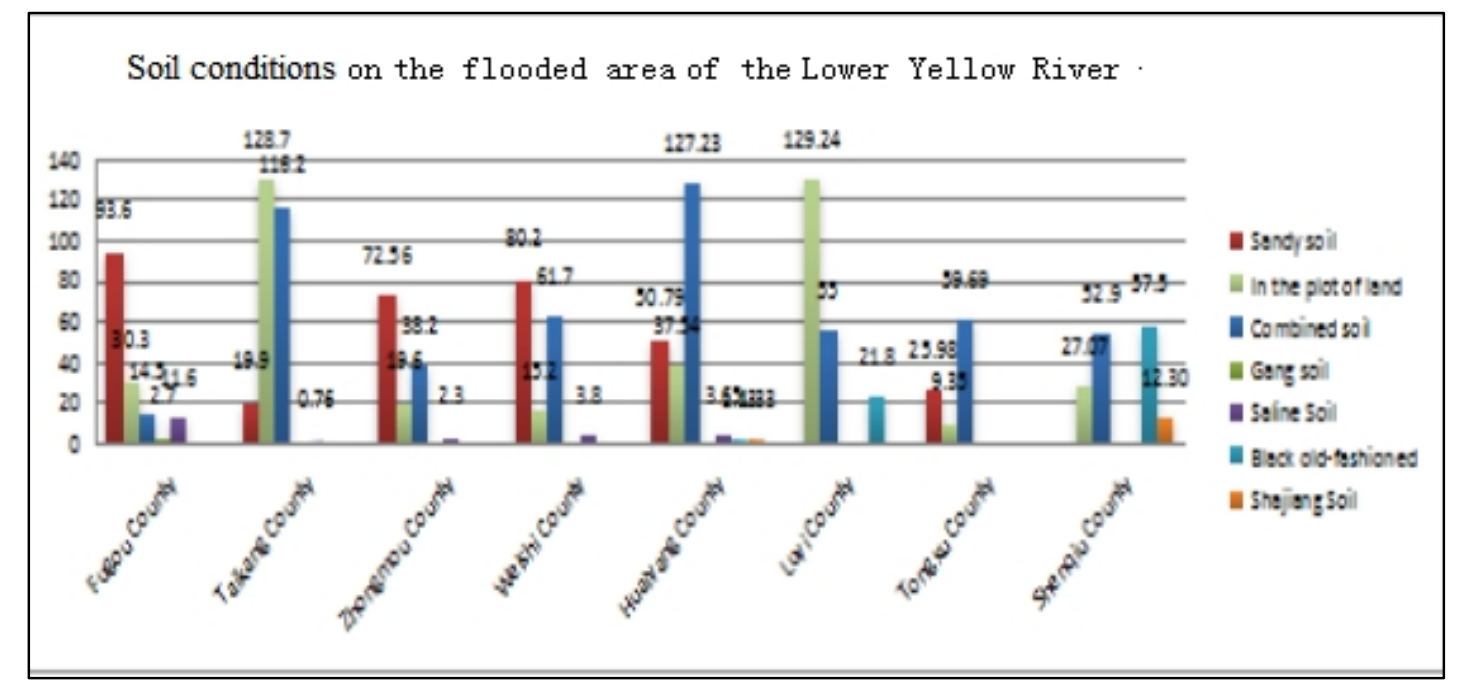

Fig. 2 Soil conditions on the flooded area of the Lower Yellow River

As shown in the Fig.2, severe land desertification and poor soil water retention reduce fertilizer effect naturally. Saline-alkali soils damage the physiological function and the soil structure. It not only impacts crop respiration and the absorption of water and nutrients, but also leads corrosion of crop roots, causing crops withering and even die. The change of soil quality in Yellow River area, especially the desertification and salting of soil, severely restrict the harvest of crops. Although the land can be cultivated, the yield of agricultural crops is reduced, the number of annual crops loss especially wheat in 1938-1946 is the most serious. Alluvial land without flashing becomes waterlogged low-lying areas. Due to poor drainage, saline condition is very serious.

Famine caused by Yellow River flood forces the nervous relationship between people and vegetation, leading to further environmental deterioration and gradually deriving wind, drought, locusts, floods and other natural disasters. From 1939 to 1947, flood, drought, wind, frost and other disasters in flood area occurred frequently, and the phenomenon of many disasters in one year became common, which also reflected serious environmental deterioration in Yellow River flood area.

\section{Governance measures}

In order to improve the ecological environment in the flood area, the national government and the people in flooding area have taken a series of measures:

Policy. The appropriate management committees and relevant departments hag been set up and a clear liability regime has been implemented. Governments at all levels strengthen leadership and co-ordinate arrangements, and finance, science and technology, agriculture, forestry, water, land, mineral resources, environmental protection and other departments, which are actively involved in the ecological environment construction, stepping up to curb the deterioration of the ecological environment. After closure of Huayuankou, people returned home. But there were no houses, no 
food, no farm tools or seeds for cultivation. Henan Branch actively implement the cultivation of agricultural land, take the hoisting machine, cattle and labor to cultivate and other measures to promote the rehabilitation of land from the flooding area ${ }^{[6]}$. After the founding of China the government have planted more trees and grass on both sides of the Yellow River, Huai River, Hai River tributaries, and surrounding towns and villages to increase forest coverage and improve the ecological environment of the flood area.

Construction. A large amount of irrigation and drainage systems in flood area are reconstructed to achieve the purpose of water conservation in flooding area plains. To achieve rehabilitation and good results, farmland irrigation and drainage systems in flood zone must also be restored. After nine years of flood in the Yellow River, the irrigation and drainage systems were destroyed. After plugging of Huayuankoua, under the assistance of relief agency, the Yellow River Water Conservancy Bureau carried out the arrangement of waterway in flood area, in addition to conducting shafting sinking training class and other measures, to improve irrigation systems in the flood area.

\section{Conclusion}

During the War anti Japanese Army, floods overflowed southward of the Yellow River, inundated the arable land in flood area, damaged water conservancy facilities, destroyed the local agricultural production and ruined people's living condition. In addition, frequent natural disasters caused by the deterioration of ecological environment resulted in crop yields plummeting, even zero harvest. Up to 9 years of overflowing southward of the Yellow River has caused serious damage to the ecological environment. Its results make generations of people in the pan spend 60 years of efforts transforming, by turning the sand silt, construction of farmland protective and farmland water conservancy facilities, governance saline, series of transformation and control measures to increase soil fertility, ecological environment in the flooding area has been improved gradually.

\section{Acknowledgements}

This work was financially supported by the Innovation Scientists and Technicians Troop Construction Projects of Zhengzhou City (121PLJRC527).

\section{Reference:}

[1] CAO H., The past and the present of Huayuankou [J].Reference to history teaching in middle school, 1996, 06

[2] XU H., Research on landscape dynamics of agricultural ecosystems in the flooded area of the Yellow River from 1938 to 2002 [D] Henan: Henan University. 2008.

[3] QU Cg., Summary of Huayuankou Event in1938 [J]. Journal of Xuchang University (Social Science Edition), 2003,03.

[4] BAO My., Study on dike breach and recover of the Yellow River, China Jun.1938-Sep.1947 [D]. Shandong University, 2013

[5] YIN Hn., The improvement of agricultural technology in the farm state-operated on the flooded area of the Yellow River in Henan Province,1951-1965 [D]. Henan University, 2009.

[6] LI Yh., Research on the ecological environment in the flooded area of the Yellow River in East Henan [J]. Intelligence, 2010 